\title{
Acceso a Información Pública en Chile. Comentarios sobre una Institucionalidad Pendiente
}

Juan Pablo Olmedo B.*

\begin{abstract}
Resulta de enorme interés hoy en día realizar un comentario respecto a los esfuerzos sociales destinados a transitar desde una tradición de secreto a una cultura de la transparencia y los desafíos para promover y proteger efectivamente el derecho de acceso a información pública en nuestro país.
\end{abstract}

Siendo recipiente de dos campos de incidencia que lo reconocen y promueven a nivel global, vinculados a la agenda de integridad pública y a la protección de los derechos humanos, el derecho de acceso a la información pública se encuentra en una privilegiada posición en el entorno social que reconoce su valor como uno de los fundamentos de las sociedades democráticas abiertas, al favorecer la libre circulación de las ideas, el debate público informado, la rendición de cuentas y la transparencia dentro del Estado ${ }^{1}$.

La experiencia comparada muestra un creciente proceso de reforma legal que ha llevado a cerca de 65 países a dictar estatutos legales que consagran el derecho de acceso a información pública ${ }^{2}$, algunos de las cuales consideran la generación de institucionalidades que, con independencia y autonomía, fortalecen de manera activa el derecho de acceso a información, favoreciendo y dando impulso a la reconversión cultural.

Chile no es la excepción. A contar del año 1999, a propósito de la entrada en vigencia de la Ley № 19.653 sobre Probidad Administrativa de los Órganos de la Administración del Estado, que modificó la Ley № 18.575 sobre Bases Generales de la Administración del Estado, nuestro país cuenta con mecanismos que promueven la transparencia en la función pública, disposiciones que se han visto reforzadas y complementadas por el nuevo artículo $8^{\circ}$ de la Constitución Política incorporado por la Ley № 20.050 del 2005, que concede rango constitucional a los principios de Probidad y Publicidad ${ }^{3}$.

Transcurridos poco más de 10 años desde las recomendaciones de la Comisión de Ética Pública ${ }^{4}$, la reforma constitucional, si bien no reconoce explícitamente el derecho de acceso a información pública, refuerza considerablemente su protección legal, da término a un primer estadio fundacional de consagración del derecho y exige el perfeccionamiento de la institucionalidad generada.

Encontrándose en trámite una iniciativa de proyecto de ley, de autoría de los senadores señores Jaime Gazmuri Mujica y Hernán Larraín
* Abogado, LLM, Presidente de Pro Acceso, socio de la oficina "Colombara/ Olmedo, Abogados". Agradezco al egresado de derecho de la Facultad de Derecho de la Universidad de Chile, don Osvaldo de la Fuente Castro, por su colaboración en el desarrollo de estas ideas.

1 Centro de Derechos Humanos, Facultad de Derecho Universidad de Chile y Corporación Chile Transparente. Transparencia, Rendición de Cuentas y Lucha contra la Corrupción en América. Informe de la Reunión Regional que tuvo lugar en Santiago de Chile entre el 3 y 5 de diciembre de 2004 Redacción José Zalaquett, LOM Ediciones, Santiago, 2005.

2 En el marco de los Estados Miembros de la OEA destacan las recientes legislaciones de Trinidad y Tobago, México, Panamá, Perú, Jamaica, Ecuador, y República Dominicana. Canadá y Estados Unidos cuentan con estas leyes desde hace muchos años.

Este comentario está disponible en: www.anuariocdh.uchile.cl 
3 Ley $N^{\circ} 20.050$, publicada en el Diario Oficial el 26 de agosto de 2005.

4 Creada por D.S. $N^{\circ} 423$ del año 1994 del Ministerio del Interior.

5 Demanda de la CIDH interpuesta con fecha 8 de julio de 2005 ante la Corte IDH. Caso Marcel Claude y otros con Chile (12.108), parr. 69.
Fernández (Boletín № 3.773-06), aprobado ya por el Senado y en tramitación en la Cámara de Diputados, resulta oportuno una reflexión respecto de la experiencia acumulada del funcionamiento de la actual institucionalidad de reconocimiento y protección del derecho de acceso a información pública, con miras a proponer algunas correcciones que puedan ser consideradas para favorecer o perfeccionar el proceso de reforma legal en curso.

\section{El Derecho de Acceso a Información Pública}

El derecho de acceso a información pública encuentra su mayor desarrollo en el Sistema Interamericano de Protección de los Derechos Humanos. En el marco del artículo 13 de la Convención Interamericana sobre Derechos Humanos, que garantiza la libertad de expresión y el derecho a buscar, recibir y difundir información, la Comisión Interamericana de Derechos Humanos (CIDH), órgano de promoción de los derechos humanos de la OEA, ha reconocido la existencia de un derecho particular y autónomo de acceso a la información pública en el marco del orden público regional que "impone una obligación positiva a los gobiernos de brindar esa información a la sociedad civil" por ser "esencial para la libre circulación de ideas y el debate público informado" ${ }^{5}$.

Los principios rectores que regulan el derecho son el de "máxima revelación de la información", que se traduce en una presunción de que toda información será divulgada por el gobierno, que no es absoluta y, por lo mismo, admite restricciones a su ejercicio sobre la base de los mismos criterios que afectan a la libertad de expresión, esto es, encontrarse expresamente definidas en la ley y ser necesarias para asegurar: a) el respeto a los derechos o a la reputación de los demás, o b) la protección de la seguridad nacional, el orden público, o la salud o la moral públicas. Adicionalmente, la interpretación de la aplicación de las restricciones en casos concretos se rige por el principio de "proporcionalidad", lo que significa que la limitación debe propender a objetivos legítimos y que la carga de la prueba corresponde al Estado, quien debe acreditar que la divulgación requerida constituye una amenaza de causar sustancial perjuicio al objetivo protegido que, en todo caso, debe sobrepasar el interés público que protege la presunción de apertura y que exige develar la información.

El estándar generado por la CIDH recoge la madurez lograda tras más de siete años de desarrollo y reflexión generada en el seno de la OEA e involucra el esfuerzo colectivo de los Estados miembros y órganos de la OEA y, en particular, de la Relatoría para la Libertad de Expresión. Recientemente, esta apreciación ha sido sometida a la ratificación de la Corte Interamericana de Derechos Humanos en el caso № 12.108 "Claude Reyes y otros contra Chile".

Siendo así, próximamente, el Sistema Interamericano de Protección de los Derechos Humanos generará un precedente judicial que, es de esperar, ratifique la existencia del derecho de acceso a la información pública y 
sirva, a su vez, de criterio interpretativo para avances similares en la esfera internacional o de otros sistemas regionales de protección a los derechos humanos y de estímulo para las reformas legales en el ámbito nacional.

De otro lado, y desde el ámbito del campo de la integridad pública, se reconocen también impulsos internacionales y regionales para dar un reconocimiento al derecho de acceso a la información pública. En particular, en el marco del artículo III №11 de la Convención Interamericana contra la Corrupción, el acceso a la información pública se concibe como una herramienta de la sociedad civil destinada a colaborar en los esfuerzos sociales para prevenir la corrupción y, por lo mismo, resulta esencialmente instrumental a tal política. También la Convención de Naciones Unidas contra la Corrupción, que entró recientemente en vigencia, expresamente contempla, en su artículo $10^{\circ}$, la obligación de establecer procedimientos que permitan el acceso a la información.

Tal característica ha sido reconocida e incorporada desde temprano en la Política Pública de Probidad y Transparencia que impulsa el Estado de Chile. La Comisión de Ética Pública fue enfática en cuanto a que "el buen éxito de una política de promoción de la ética pública depende, en parte fundamental, del nivel de información, compromiso, y organización de la sociedad civil para desempeñar un rol de activo contralor en esta materia", por lo que la "transparencia, sistematicidad y fluidez de la información pública es, por tanto, un objetivo de primera importancia", recomendando al Estado la necesidad de "legislar sobre el acceso de la ciudadanía a la información, estadísticas e informes sobre materias públicas que hayan sido generados en, u obren en poder de, la Administración Pública" ${ }^{\prime \prime}$, sugerencia que explica las disposiciones que sobre esta materia se encuentran contenidas en el ordenamiento jurídico.

\section{Reconocimiento Legal del Derecho de Acceso a Información}

A contar del año 1999 a la fecha, el Estado de Chile ha impulsado tres propuestas legislativos que inciden en la consagración del derecho de acceso a información pública y que se concretizan en los actuales artículos 3, 13, 14 y 53 de la Ley № 18.575, luego de la modificación introducida por Ley № 19.653 sobre Probidad Administrativa de los Órganos del Estado de 1999; los artículos 16, 17 y 39 de la Ley № 19.880 sobre el Procedimiento Administrativo de los Órganos del Estado, del año 2003, y, más recientemente, lo dispuesto en el artículo $8^{\circ}$ de la Constitución Política, luego de la reforma constitucional del año 2005.

Un análisis de las disposiciones citadas que incluye, en cuanto a sus efectos, la entrada en vigencia del artículo $8^{\circ}$ de la Constitución ${ }^{7}$, permite concluir que el Estado reconoce el derecho de "acceso ciudadano a la información administrativa", como un elemento que expresa el interés general del principio de publicidad y de probidad y no como un derecho humano, calidad que, no obstante, ha sido reconocida por la
6 Informe de la Comisión Nacional de Ética Pública, 1994

7 Informe de la Comisión de Constitución, Legislación, Justicia y Reglamento del Senado, Boletín No S 830-10. 
8 "Olmedo con Aduana", ROL 3942004, sustanciado ante

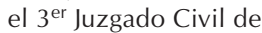
Valparaíso; Claude con Banco Central, ROL 19-2003, sustanciado ante el $7^{\circ}$ Juzgado Civil de Santiago.

9 Publicado en el Diario Oficial el 7 de mayo de 2001.

${ }^{10}$ D.S. N ${ }^{\circ} 134$ de 2005 de la SEGPRES, D.O. 05 de enero de 2006

11 Informe Chile, SG/ MESICIC/doc.84/03 rev. 4, 6 de febrero de 2004. El Comité recomendó al Estado de Chile "fortalecer las garantías previstas para el ejercicio del derecho al acceso a la información del Estado, de tal manera que el acceso a la misma no pueda ser denegado por causales diferentes a las que se determinen por ley, o con base en criterios de amplia discrecionalidad", p. 38. jurisprudencia nacional, en aquellos casos en que ha conocido infracciones al mismo ${ }^{8}$.

El derecho se concede respecto de información que no se encuentre de manera permanente a disposición del público; se extiende a los órganos del Estado, incluyendo al Poder Ejecutivo, Legislativo y Judicial, así como los órganos con autonomía constitucional y a la función pública, otorgando un contenido finalista al concepto de Administración del Estado; alcanza a los actos y resoluciones, sus fundamentos y los procedimientos, e incluye a las empresas del Estado y al sector privado que presta servicios de utilidad pública, cuando la información requerida se vincule al ejercicio de las facultades fiscalizadoras de los entes de supervigilancia estatal. Tras la entrada en vigencia del nuevo artículo $8^{\circ}$ de la Constitución, los objetivos legítimos de restricción se encuentran establecidos directamente en la Constitución Política e incluyen el debido cumplimiento de las funciones de los órganos requeridos, los derechos de las personas, la seguridad de la nación o el interés nacional, causales que deberán ser precisadas por una ley de quórum calificado.

La jerarquía constitucional otorgada a las causales de reserva resulta meritoria. Por su intermedio, ha sido rectificada una grave falencia de la institucionalidad de acceso a la información pública: la habilitación reglamentaria del secreto y reserva que contenía el artículo 13, inciso final, de la Ley № 18.575, concretizada en el Reglamento sobre Secreto y Reserva de los Actos y Documentos Administrativos DS № 26 de 2001 de la SEGPRES ${ }^{9}$ y más de 90 resoluciones dictadas por los Servicios Públicos, irregularidad que, tras la entrada en vigencia de la Constitución, ha sido formalmente derogada ${ }^{10}$.

Se aprecia entonces que, en lo que concierne al reconocimiento formal del derecho, el campo de los derechos humanos y aquel referido a la integridad pública coinciden en un estándar mínimo de reconocimiento del derecho de acceso a información pública. Sin embargo, la causal de reserva referida al debido cumplimiento de las funciones del órgano requerido, si bien puede ser entendida como equivalente o incorporada en aquella que protege el orden público, es poco clara, admite abuso, concede una excesiva discrecionalidad en su interpretación y ha llamado la atención del Comité de Expertos de la Convención Interamericana contra la Corrupción ${ }^{11}$. Del mismo modo, la causal de reserva fundada en los derechos de terceros que recoge el artículo 13 inciso 11 de la Ley № 18.575, que habilita la declaración de reserva de oficio por parte del órgano requerido cuando, en su criterio, la información afectare sensiblemente los derechos de terceros, otorga una excesiva protección a los terceros que deben siempre justificar su negativa, y puede, también, generar un uso abusivo por parte de la autoridad. 


\section{Protección del Derecho de Acceso a la Información Pública}

\section{a) Solicitud Administrativa}

Conforme a lo dispuesto en el artículo 13 de la Ley № 18.575 , el procedimiento administrativo de solicitud de acceso a la información pública se inicia mediante la presentación de una solicitud escrita del interesado dirigida al jefe del servicio en la oficina de partes del órgano requerido. El jefe del servicio deberá pronunciarse sobre la petición, sea entregando la documentación solicitada o negándose dentro del plazo de 48 horas contado desde la presentación de la solicitud. En caso de que el requerimiento se refiera a antecedentes que contengan información que pueda afectar los derechos de terceros, el jefe superior del servicio deberá comunicar tal circunstancia a los afectados, quienes tendrán un plazo de tres días para formular oposición, la que deberá presentarse por escrito "y no requerirá expresión de causa". Deducida la oposición en tiempo y forma, el jefe superior del servicio queda impedido de proporcionar la información, salvo resolución judicial. Si no hay oposición, el jefe superior del servicio deberá proporcionar la documentación solicitada, a menos que concurra alguna otra causal legal de reserva, caso en el cual la negativa deberá formularse por escrito y fundadamente, especificando las razones que motiven su decisión.

La experiencia acumulada en el ejercicio de las solicitudes administrativas de ejercicio del derecho de acceso a la información muestra una resistencia de los órganos del Estado a dar respuesta a los requerimientos de acceso a la información pública de $\operatorname{los}_{\text {ciudadanos }}{ }^{12}$, una falta de fundamentación en las negativas de acceso y un ejercicio abusivo de las causales de protección fundadas en derechos de terceros ${ }^{13}$. Siendo los tribunales de justicia quienes en definitiva deban pronunciarse sobre el ejercicio del derecho, la lógica inclinación de los jefes de servicios, ante las solicitudes de acceso a información pública, ha sido la de esperar la resolución judicial.

La intervención de oficio de la Comisión Asesora Presidencial para la Protección de los Derechos de las Personas ${ }^{14}$ no ha sido suficiente para revertir la tendencia que se explica, además, por la carencia de incentivos institucionales para dar cumplimiento a la obligación de respuesta y una percepción de "eximente de responsabilidad" de los órganos requeridos ante eventuales reclamos de terceros que se sientan afectados con esa entrega de información sensible alusiva a ellos o sus actividades ${ }^{15}$.

\section{b) Amparo Jurisdiccional}

El remedio judicial en caso de infracción al ejercicio del derecho de acceso a información pública se encuentra contenido en el artículo 14 de la Ley № 18.575 , disposición que consagra un procedimiento especial de amparo ante los jueces de letras, instancia habilitada para revisar la calificación de reserva y/o el incumplimiento de la obligación de respuesta oportuna. La acción de amparo exige acompañar los medios de prueba en poder del interesado, se tramita de manera sumarísima y exige al
12 Open Society Institute and PARTICIPA. Chilean Report "Monitoring the Access to Public Information", noviembre 2004.

13 "Vigneux con Contraloría", ROL 322002, sustanciado ante el $23^{\text {er }}$ Juzgado Civil de Santiago.

${ }^{14}$ Creada mediante DS № 65 de fecha 11 de mayo de 2001.

15 Oficio № 037 de fecha 15 de febrero del presidente de la Comisión para la Protección de los Derechos de las Personas dirigido a la Corte IDH en el caso Marcel Claude y otros con Chile (12.108). En el mismo sentido se pronuncia el profesor Davor Harasic, en su informe pericial presentado ante la Corte IDH en el mismo caso sobre "Legislación y Práctica del Secreto en la Gestión Pública, donde expresa que "al ser los tribunales de justicia los que tienen la última palabra en materia de acceso a la información pública, los jefes de servicio optan lisa y Ilanamente por esperar la eventual resolución judicial", p. 6. 
16 Para un análisis de la jurisprudencia ver de Jorge Contesse Singh, "La Opacidad del Administrador y la indulgencia Judicial: Jurisprudencia y Práctica sobre Acceso a Información Pública en Chile", en La Libertad de Expresión en Chile, Facultad de Derecho, Universidad Diego Portales, 2005.

17 "Vigneaux con Contralor General de la República", donde la sentencia definitiva se dictó siete meses después de la presentación de la acción de amparo para el acceso a la información pública, superando con creces el período contemplado en la ley. En "Moral con SEC", la sentencia definitiva se dicto después de 8 meses de la presentación de la acción de amparo.

18 En "Olmedo con SEC" y en "Claude Marcel con CONAF", ambos seguidos ante el $29^{\circ}$ Juzgado Civil de Santiago, el tribunal no acogió la solicitud de aplicar las sanciones establecidas en el artículo 14 de la Ley № 18.575 frente al incumplimiento de la obligación de entrega ordenada en la sentencia.

19 El Profesor Tomás Vial Solar, en el informe pericial presentado en el caso seguido ante la Corte IDH "Claude Reyes contra Chile", sobre los "efectos de la reforma constitucional relativa al principio de publicidad en la Constitución Política". En dicho informe se señalan como consecuencias de la falta de un reconocimiento
Tribunal dictar sentencia dentro del plazo de cinco días contado desde que se evacue el informe por la autoridad requerida. Con excepción de la sentencia definitiva, las resoluciones en este procedimiento se notifican por el estado diario por lo que, en la práctica, surgen efectos inmediatos y se dictan en única instancia, no procediendo recurso alguno en contra de ellas, salvo la queja. La apelación deberá interponerse ante la Corte de Apelaciones y se dará cuenta del recurso de manera preferente, sin esperar la comparecencia de ninguna de las partes. La Sala de la Corte que conozca del recurso, si lo estima conveniente o se le solicita con fundamento plausible, podrá ordenar traer los autos en relación para oír a los abogados de las partes, en cuyo caso la causa se agregará extraordinariamente a la tabla respectiva. En caso de que la causal de reserva invocada sea que la publicidad afecta la seguridad de la Nación o el interés nacional, se contempla un procedimiento excepcional de amparo que se tramita directamente ante la Excma. Corte Suprema.

Los precedentes judiciales emblemáticos generados durante el año 2001 a la fecha ${ }^{16}$ muestran que la respuesta jurisdiccional, en los casos de amparo de acceso a información pública sometidos a su conocimiento, resulta insuficiente para proteger el derecho de acceso a información pública.

El recurso a los tribunales de justicia no ha sido incluido dentro de los programas de asistencia judicial gratuita que impulsa el Estado, factor que limita el acceso a la jurisdicción a los ciudadanos, restringiéndose la acción, en la práctica, a las organizaciones no gubernamentales que cuentan con recursos que permitan solventar los gastos del proceso y que se orientan a la defensa del interés público. No obstante el reconocimiento de su naturaleza de derecho humano, los pronunciamientos sustantivos de los tribunales, particularmente de las Cortes de Apelaciones, muestran un preocupante respaldo a los criterios de reserva y una interpretación restrictiva del derecho, en infracción al principio de máxima revelación. A su vez, los principios que regulan el derecho no han sido incorporados dentro de las instancias institucionales de capacitación y formación de los jueces, resultando novedosos para la Magistratura Ilamada a su conocimiento y fallo en primera instancia, factor que conlleva, a su vez, un retardo injustificado en la dictación de las sentencias ${ }^{17}$. Por último, hay casos en que, no obstante obtenerse sentencia favorable, se constata un incumplimiento de hecho a lo ordenado en cuanto a proceder a la entrega íntegra de la información requerida. La suma de todo lo anterior hace del todo ineficaz el recuso de amparo de acceso a la información pública ${ }^{18}$.

\section{Las Prácticas de Secreto de la Gestión Pública}

Las innovaciones legislativas antes referidas no consideraban en su origen el derecho de acceso a información pública y, por lo mismo, no fueron acompañadas de la adopción de medidas y mecanismos estatales destinados a asegurar el derecho y revertir la tradición de secreto en la Administración del Estado que, conforme fuera constatada durante el 
año 1994 por la Comisión de Ética Pública, afecta a todos los Órganos del Estado ${ }^{19}$.

En lo que concierne a la Administración durante el período de 2001 al 2005, la práctica del secreto se expresó en la conducta seguida por los Servicios Públicos tras la entrada en vigencia del Reglamento sobre Secreto y Reserva de los Actos y Documentos Administrativos ${ }^{20}$, de dictar más de 90 Resoluciones de Reserva y Secreto. No obstante la derogación formal del estatuto reglamentario de reserva, y su reemplazo por una recomendación del Ministerio Secretaria General de la Presidencia denominada "Guía de Reglas y Criterios Aplicables en Materia de Publicidad y Acceso a la Información Administrativa" ${ }^{21}$, el instrumento no tiene carácter vinculante y carece de estímulos que hagan prever una modificación del comportamiento de los servicios públicos.

Adicionalmente, y no obstante la entrada en vigencia de la reforma constitucional, los últimos meses dan cuenta de nuevos ejes de prácticas de secreto que involucran a otros órganos del Estado.

En efecto, la interpretación de la Excma. Corte Suprema ${ }^{22}$ en cuanto a dar carácter reservado a las calificaciones de los altos magistrados y la insuficiencia de las audiencias ${ }^{23}$ generadas por el Senado para la ratificación de las postulaciones de las altas autoridades del país, como son los miembros de la Excma. Corte Suprema y del Tribunal Constitucional, en cuanto a generar información pública relevante respecto de los postulantes nominados, muestra la existencia de disposiciones reglamentarias y prácticas contrarias el derecho de acceso a información pública ${ }^{24}$ que afectan sensiblemente el interés público y ameritan un ejercicio colectivo de control social.

\section{La Reforma Legislativa}

Mediante moción parlamentaria de los senadores Hernán Larraín y Jaime Gazmuri ${ }^{25}$, el Congreso Nacional se encuentra conociendo un proyecto de ley destinado a generar un estatuto de acceso a información pública, actualmente radicado en la Cámara de Diputados en segundo trámite constitucional, y que se justificó, en su oportunidad, como una reacción del Legislativo frente a los abusos incurridos durante la vigencia del Reglamento sobre Secreto y Reserva de los Actos y Documentos Administrativos.

La iniciativa parlamentaria no pretende ser un cuerpo legal autónomo sobre acceso a información pública, sino más bien una reforma a diversas leyes: Ley № 18.575 de Bases Generales de la Administración del Estado, Ley № 19.880 de Bases del Procedimiento Administrativo, Ley Orgánica Constitucional del Congreso, Código Orgánico de Tribunales, Ley Orgánica Constitucional de Municipalidades y Decreto Ley № 488 de 1925.

El proyecto reconoce el derecho de acceso respecto de la información que no se encuentre en forma permanente a disposición del público, explícito del derecho: a) el Estado no se ve en la obligación de promoverlo ni de crear las condiciones para su plena protección; b) desprotección del derecho frente a otros que tienen un reconocimiento como derecho fundamental explícito; c) no se encuentra cubierto por la garantía del respeto del contenido esencial del derecho que contempla el art. 19 № 26, pp. 18-19.

${ }^{20}$ A modo ejemplar, el artículo $8^{\circ}$ del Reglamento establecía que "[s]ólo podrán ser declarados como secretos o reservados los actos y documentos cuyo conocimiento o difusión pueda afectar el interés publico $\mathrm{O}$ privado de los administrados", incorporando dentro del interés público causales de reserva como la defensa, la política exterior, relaciones internacionales, política monetaria, entre otros.

21 Oficio $N^{\circ} 072$ del 24 de enero de 2006 de la SEGPRES.

22 Resolución de fecha 12 de enero de 2006 de la Corte Suprema.

23 Una revisión de los registros públicos disponibles, emanados de las audiencias generadas con posterioridad a la entrada en vigencia de la reforma constitucional, se limita a dejar constancia de aspectos formales -relacionados con la discusión de la naturaleza pública o reservada de la audiencia- y no dan cuenta de los aspectos sustantivos comprometidos como 
son, entre otros, los aportes de visión país de los nominados, sus posiciones personales frente a las

sensibilidades sociales, el intercambio de opiniones y las observaciones de los miembros de la Comisión, información que resulta esencial para su ratificación y que da cuenta del interés público comprometido en las designaciones.

24 Véase la Pauta para las Audiencias que la Comisión de Constitución, Legislación, Justicia y Reglamento celebre con las personas que el Presidente de la República proponga para el cargo de Ministro de la Excma. Corte Suprema de Justicia, preparada por el Senado. El documento no tiene fecha e inhibe a los senadores de consultar a los ministros respecto de sus "planteamientos doctrinarios" o "temas valóricos". Asimismo, el Boletín N4059-07 sobre la reforma a la ley del Tribunal Constitucional introduce un nuevo artículo 4 del siguiente tenor: "Son públicos los actos y resoluciones del Tribunal, así como sus fundamentos y los procedimientos que utilicen. Sin embargo, el Tribunal, por mayoría de votos, podrá decretar el carácter de reservadas o secretas a determinadas actuaciones o documentos con sujeción a los prescrito en el artículo 8, inciso segundo de la Constitución".

25 Boletín № 3773-06. incorpora el principio de máxima revelación, regula las causales de reserva legal y establece el principio de proporcionalidad en su aplicación; rectifica algunas falencias del procedimiento de solicitud administrativa; establece un plazo de reserva de 20 años, y consagra una obligación de información mínima que se debe tener a disposición del público por parte de los órganos de la Administración del Estado. No obstante, no incorpora al sector privado como sujeto pasivo del derecho, excluye la obligación de generar información de interés público y no establece estímulos para asegurar su cumplimiento por parte del administrador.

Teniendo presente todo lo anterior, la iniciativa en curso resulta insuficiente para revertir la tradición de secreto de la función pública y debe ser reorientado para que a la luz del nuevo artículo $8^{\circ}$ de la Constitución, recogiendo la experiencia comparada de países como México y Gran Bretaña, así como las obligaciones internacionales asumidas, avance en la concreción de un estatuto del derecho de acceso a información pública autónomo, que respete su especial naturaleza de derecho humano e instrumento de política pública; reconozca la obligación estatal de generar información de interés público (sobre todo en materia de derechos humanos) e incorpore una institucionalidad activa que dé impulso a las políticas públicas sobre la materia; reoriente la cultura del secreto; formule e implemente mecanismos de coordinación y promoción del derecho en todos los niveles de nuestra comunidad, y fiscalice e intervenga en su protección en casos en que se encuentre comprometido el interés público nacional.

\section{Conclusión}

Mediante la incorporación del principio de probidad y publicidad en el artículo $8^{\circ}$ de la Constitución Política, el derecho de acceso a información pública ha sido expandido en cuanto a sus sujetos pasivos, alcanzando a todos los órganos del Estado y, en cuanto a su objeto, a los actos, procedimientos y fundamentos de los órganos del Estado. Asimismo, el Constituyente estimó necesario determinar expresamente las causales de reserva legal, eliminando aquella referida al Reglamento y, encomendando a la ley, que deberá ser de quórum calificado, la concreción de las causales de reserva. No obstante el avance, el derecho sigue limitado a los antecedentes que no obren de manera permanente a disposición del público e identificado con el principio de probidad y publicidad, características que, sumadas a la práctica de reserva en la gestión pública y una ausencia de estímulos para garantizar su respeto y observancia, lo hacen insuficiente para revertir la tradición de secreto en el país y garantizar su naturaleza de derecho humano. 